Brit. F. vener. Dis. (1970) 46, 303

\title{
Isolation of spirochaetes from primates and other mammalian species ${ }^{(1)}$
}

\author{
ALBERT W. HANSON \\ Venereal Disease Research Laboratory, Venereal Disease Branch, State and Community Services Division, National \\ Communicable Disease Center, Health Services and Mental Health Administration, Public Health Service, U.S. \\ Department of Health, Education, and Welfare, Atlanta, Georgia, 30333, U.S.A.
}

Reports of spirochaetal antibodies in normal animals (Fribourg-Blanc, Niel, and Mollaret, 1966; Thivolet, Sepetjian, and Guerraz, 1967) indicate that infections with spirochaetes, other than the more commonly known cuniculosis of rabbits, do occur in nature. This is partially confirmed by the demonstration of spirochaetes in the liver tissues of normal chickens (Steinhaus and Hughes, 1947), digestive tracts of dogs (Pindak, Clapper, and Sherrod, 1965), popliteal lymph nodes of Cynocephalus monkeys from Guinea (Fribourg-Blanc and Mollaret, 1967), hoofs of sheep (Beveridge, 1934), oral cavity and genitalia of man (Doenges, 1939); Hampp and Mergenhagen, 1961; Hanson and Cannefax, 1964; Rosebury, 1962), alimentary tract of cats (Weber and Schmittdiel, 1962), and intestinal tract of rats, goats, mice, and guineapigs (Macfie, 1916; Parr, 1923).

In a comprehensive study of the bacterial flora of the alimentary tract of the chimpanzee, Gall (1964) did not mention finding any spirochaetal organisms. Coulston, Soike, and Day (1967), in a similar study, did not find spirochaetal flora in the reproductive tract of the chimpanzee. Demonstrations by others of spirochaetal antibodies (Fribourg-Blanc and others, 1966; Kuhn, Brown, and Falcone, 1967) in monkeys or great apes would indicate that this group of organisms probably inhabits the body of primates.

When spirochaetes are part of the microflora of clinically healthy animals, their significance and function to the host and to the other microflora present need to be known. Also, because the tissues of various mammals and non-mammals are used for antigen production, because of possible future use of animals as donors of organs or biological systems to men, the normal microbiological flora of these animals should be characterized to preclude unexpected complications from the transfer of agents which could be virulent for man. This report is a contribution towards this goal.

Received for publication November 4, 1969

(1) Trade names are used for identification only and do not represent an endorsement by the Public Health Service or the U.S. Department of Health, Education, and Welfare.

\section{Material and methods}

Animals in this study can be grouped into three general categories:

(1) Animals of the specialized laboratory, including the chimpanzee, monkey, dog, and cat.

(2) Animals more commonly encountered in the general medical laboratory, including the rabbit, rat, mouse, hamster, guinea-pig, and gerbil.

(3) Feral animals, including the fox, raccoon, skunk, opossum, and bat.

Samples of animal tissues or fluids were cultured twice or more at 3 to 5 day intervals. This was shown to be necessary (Gall, 1964; Kaplan, Geating, and Brooker, 1968) because the bacterial flora of an animal can change from day to day. These investigators also demonstrated that multiple isolations from the same animal at one time were necessary to obtain an accurate representation of the microbiological flora present.

Primates used in this study were housed at the Venereal Disease Research Laboratory's Primate Facility or at the Yerkes Regional Primate Center. Dogs and cats were normal laboratory animals or stray animals obtained from a local animal shelter.

Feral animals were trapped for predator control, or for use in a survey of rabies infection in the wild-animal population of the south-eastern United States. Before use the feral animals were held under laboratory conditions for 2 to 4 weeks, and they received raw ground beef, commercial dog ration, and water, ad lib. The animals were not subjected to medication or immunization until samples were obtained for isolation of spirochaetes. During the 2-week period after the last attempt to isolate spirochaetes, none of the feral animals showed clinical manifestations of rabies.

Commercially produced laboratory feeds were available to all animals throughout the course of this experiment. The feeds did not contain antibiotic or chemotherapeutic supplement.

To determine the possible coexistence of cultivatable treponemes and pathogenic treponemes in clinical lesions of lower animals, three rabbits with Treponema cuniculi infections were included.

Materials for the isolation of spirochaetal flora were collected on sterile swabs from the oral cavity, anus, perianal area, and genitalia (prepuce of the male and vaginal opening and vault of the female). The material was rinsed from the swabs into a holding medium (Hanson 
and Cannefax, 1964). The medium was similar to that used for growth of the organisms. Twenty units of polymyxin B sulphate ${ }^{(2)}$ were added per $\mathrm{ml}$. medium to retard growth of the commensal nontreponemal organisms. The applicator stick was broken, with the cotton swab remaining in the transport tube. The material was held at ice temperature $\left(1-5^{\circ} \mathrm{C}\right.$. $)$ until used for inoculation. At the time of inoculation, the swab head was removed from the holding medium and was compressed against the side of the tube to remove medium and debris. Approximately $0.2 \mathrm{ml}$. transport medium was inoculated into the well of a Petri plate of soft agar medium ( 0.7 per cent.) containing 45 per cent. Spirolate broth (3), 45 per cent. brain heart infusion broth ${ }^{(3)}$ fortified with 0.025 per cent. sodium thioglycollate, 0.025 per cent. asparagine, 0.025 per cent. Tryptone (4), and enriched with 10 per cent. normal inactivated $\left(56^{\circ} \mathrm{C}\right.$. for $30 \mathrm{~min}$.) rabbit serum. Plates were prepared and incubated as previously described (Hanson and Cannefax, 1964; Hanson and Cannefax, 1965).

After 5 to 7 days of incubation, growth was observed as a delicate white haze from 1 to $3 \mathrm{~cm}$. in distance about the centre well. Some plates also contained a second, denser haze closer to the centre well. Smears of the outermost haze were prepared and examined with darkfield illumination and were found to contain Borrelia-like organisms, whereas the innermost haze contained a mixture of treponemal and Borrelia-like organisms. This arbitrary classification was based upon the microscopic morphology of the organisms present. The Borrelia-like organisms were loosely coiled, but the organisms considered to be treponemes were tightly coiled.

Using a sterile capillary pipette, 1 to $2 \mathrm{~mm}$. in diameter, the agar plugs containing the organisms were punched from the well plates at the visible edge of the outermost haze and from the denser inner band. The agar plugs were then transferred to tubes of medium of the same composition as the well plates, with the agar concentration reduced to 0.1 per cent. Inoculation of the agar plugs was midway in the column of soft agar medium. Plates and tubes were incubated at $35^{\circ} \mathrm{C}$.

The mixture of spiral organisms obtained from the primary isolation of the denser inner band was subcultured three times in the soft agar medium, with 0.001 per cent. crystal violet added. After three subcultures, all isolates were grown in the broth medium without crystal violet. Using the methods previously described (Hanson and Cannefax, 1965), organisms from broth cultures were streaked on hard agar plates for colony typing.

To determine the virulence of isolates, two normal rabbits were inoculated at two sites on the back with $5 \times$ $10^{9}$ organisms per site. A like number of organisms was inoculated into each testis of the same animal. These inocula were obtained by pooling the isolates of one animal species in approximately equal numbers. When possible, both borrelial and treponemal organisms were included in the inoculum. Test animals were observed

(2) Charles Pfizer \& Co., Inc., New York, N.Y. 10017.

(3) BBL, Division of BioQuest, Baltimore, Md. 21204.

(4) Difco Laboratories, Detroit, Mich. 48201. for 12 weeks for the development of a darkfield-positive lesion at the site of inoculation or for a palpable orchitis. All animals were bled after the observation period. Serum from this bleeding and serum obtained at the time of attempted infection were tested for treponemal antibodies by an indirect fluorescent antibody technique, using the methods of Mothershed, Yobs, and Clark (1967). Using these reagents to identify antibodies developed in the challenged animals, spirochaetes eliciting antibodies similar to or identical with Treponema pallidum, are most likely to be detected.

\section{Results}

The Table (opposite) shows that isolates were obtained from all carnivores and omnivores from at least one site. None was obtained from clinically healthy herbivores. Although three isolates were obtained from herbivores, these animals were also infected with $T$. cuniculi.

An analogy will also be noted, i.e. that an animal demonstrating cultivatable isolates in the oral cavity generally harboured cultivatable isolates in the perianal area. Conversely, if spirochaetal organisms could not be found in the oral cavity, neither were they demonstrated lower in the alimentary tract.

Inoculation of rabbits with large numbers of organisms from pure isolates did not produce evidence of lesion formation and serum antibodies reactive with $T$. pallidum were not detected. A small transitory wheal appeared after inoculation of most test rabbits. A similar type of reaction was also observed (Hampp and Mergenhagen, 1961) when spirochaetes were inoculated into the cheek pouches of hamsters.

All spirochaetal isolates obtained were Colony types I, II, or IV, as previously described (Hanson and Cannefax, 1965). Some isolation material produced all three colony types. It could not be determined if colony types existed in the original material or if they were mutants from one colony type. No correlation could be made between the colony types and the species of animals or the sites of origin of the cinical material.

With the incorporation of 0.001 per cent. crystal violet into a basal medium adequate for the cultivation of spiral organisms, a separation of the treponemal from the borrelial type of organisms was accomplished. This dye selectively inhibits the growth of borrelia-like organisms. Using this procedure, both types of organisms were isolated at one time from the same sample of tissues or body fluids.

\section{Discussion}

With the extended use of non-human animal tissues in medical research and therapeutics, the presence of spirochaetes as a component of the natural flora of 
TABLE Frequency of isolation of spirochaetal organisms

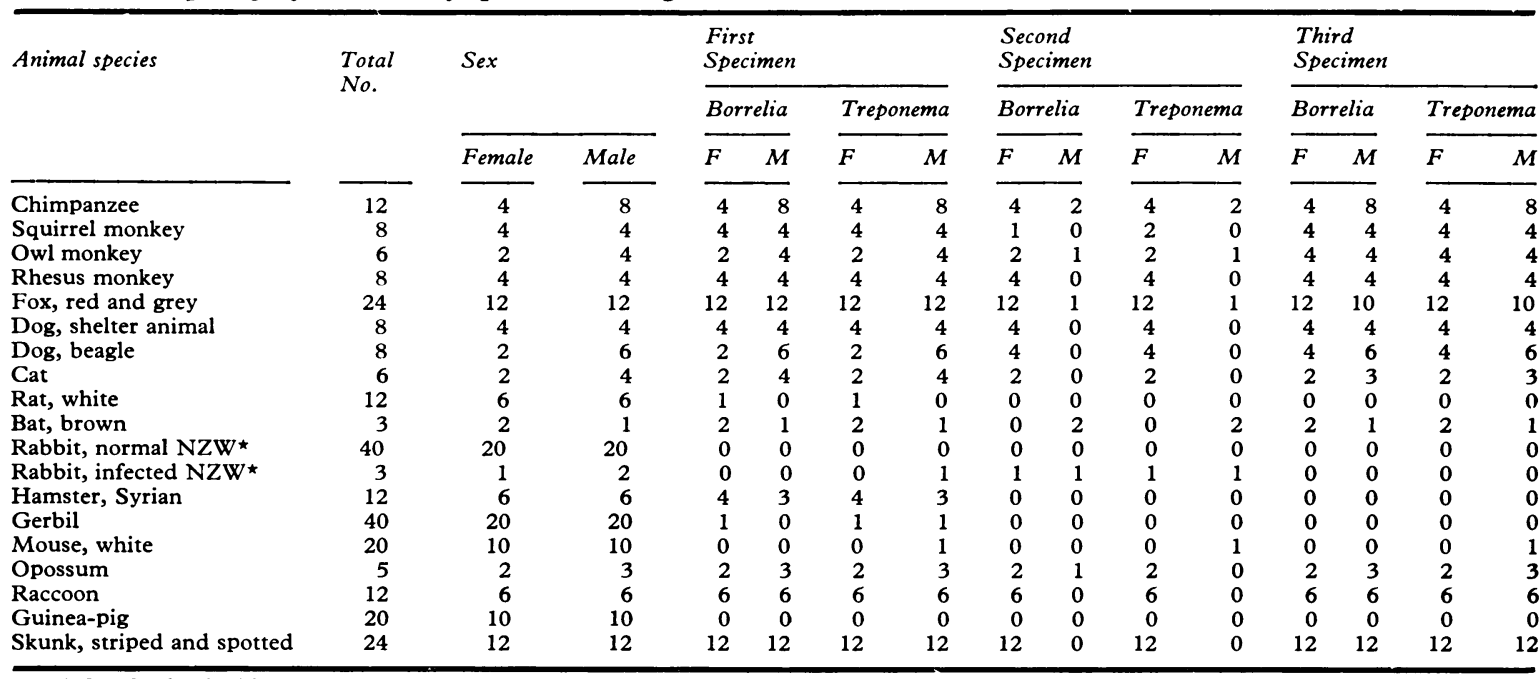

${ }^{\star}$ New Zealand white

many animals should be considered. When surveys of the natural bacterial flora of animals are performed, unless procedures for the isolation of spirochaetes are included in the design of the investigation, there will be occasions when spirochaetes are present but not detected. Utilizing methods favouring the isolation of spirochaetal organisms, the re-examination of one extensively studied animal species-the chimpanzee-allowed spirochaetes to be isolated easily from the oral cavity of all animals tested and many times from two sites (oral cavity and perianal area).

Isolates obtained from the oral cavity and the perianal area of several of the animals exhibited the same colony types. This poses the interesting question of both the origin and the significance of the location of the spirochaetal forms.

It may be assumed that intestinal spirochaetes originate in the oral cavity and have little, if any, pathogenic significance in either the oral or intestinal sites. In a study of patients with Vincent's angina and harbouring spirochaetes lower in the alimentary tract, Doenges (1939) considered that the organisms were not related. He also considered that those found in the lower tract were nonpathogenic for the patient. In their study of spirochaetes found in the digestive tracts of dogs, Pindak and others (1965) believed that the organisms were passed from the mouth through the stomach before becoming established in the lower intestine. But they were not able to determine with certainty that the organisms found in the lower digestive tract were the same as those observed in the oral cavity. These authors did not preclude the possibility that the spirochaetes originally propagated in the lower intestine and appeared in the mouth or some other part of the digestive tract as the result of anus-to-mouth re-infection, incidental to the dog's natural habit of self-licking. These same possibilities exist in the present study. Some of the animals included are known to have coprophilic tendencies under laboratory conditions (chimpanzees, monkeys, skunks, and opossums). In normal rabbits, a known coprophagous species, spirochaetal forms were not found in either the upper or the lower intestinal tract.

In order satisfactorily to resolve the question of the sites of origin of the spirochaetes, it would be necessary to characterize the isolates from each area and establish their similarity. Colonial typing alone is not sufficient to answer this question completely. Another possible avenue of approach in resolving this question would be to observe the transmission or migration of spirochaetes in susceptible axinic animals.

The colony types of all isolates in this study maintained their characteristic morphology during 3 months of weekly subculture. This suggests that different types existed in the original isolation material and were not mutants of one colony type. If, on the other hand, all colony types were not present in the original material, the conversion from one type to a more stable colony type was accomplished in a short period of cultivation in artificial media.

It was found that a separation of borrelial from treponemal types of organisms in the same isolation 
material could be accomplished by incorporating 0.001 per cent. crystal violet into the medium. However, it is not recommended at this time that crystal violet, in the concentration used, be routinely incorporated into this medium. While completely suppressing the Borrelia strain, the dye has a slight inhibitory effect on the growth of the treponemes. If the dye was used in the primary isolation medium, overgrowth by the commensal non-treponemal organisms could result before the number of treponemes competent for isolation were available.

The number of animal species shown in this and other studies to have spirochaetal organisms as part of their microflora would indicate that these organisms were widespread. If adequate methods are employed, additional species of animals may be shown to have spirochaetes as part of their microbiological flora.

Possibly, in a qualitative assessment of the presence of spirochaetes in an individual isolation, successful attempts from the oral cavity would appear the more probable and, hence, more efficient. Also, isolations from the female genitalia appear to be more successful than those from the male.

In attempting to demonstrate the virulence of the isolates obtained in this study, only rabbits seronegative for syphilis were used. The absence of virulent isolates does not preclude the possibility of virulent organisms in another species or their detection by a different mode of inoculation.

Since many of the species of rodents in this scudy were laboratory bred and reared, the results might have been different if rodents from natural sources had been included.

\section{Summary}

Nineteen mammalian species of laboratory and feral origin were examined by methods favouring the isolation of spirochaetal organisms. Positive isolations were obtained from at least one site of all carnivores and omnivores but not from the herbivores. None of the isolates produced a darkfieldpositive lesion or a rise in antibody titre for Treponema pallidum in test rabbits. This study suggests that spirochaetes are present in the microflora of many animals but will go undetected unless specific methods are used for their isolation.

The author is grateful to Romulus Skaggs, Jr., and Joseph F. Smith for their technical assistance, to U. S. Grant Kuhn III for clinical material from chimpanzees, to Keith R. Sikes for clinical material from dogs and feral animals, and to R. M. Smibert for his helpful suggestions during the preparation of this'manuscript.

\section{References}

Beveridge, W. I. B. (1934). Aust. vet. F., 10, 43

Coulston, F., Solke, K. F., and DAY, P. W. (1967). 'Holloman Air Force Base, New Mexico, Technical Documentary Report', No. ARL-TR-67-7

Doenges, J. L. (1939). Arch. Path., 27, 469

Fribourg-BlanC, A., and MollareT, H. H. (1967). WHO/VDT/RES/68.135

-, Niel, G., and Mollaret, H. H. (1966). Bull. Soc. Path. éxot., 59, 54

GaLl, L. S. (1964). 'Holloman Air Force Base, New Mexico, Technical Documentary Report', No. ARL-TDR-64-19

Hampr, E. G., and Mergenhagen, S. E. (1961). F. infect. Dis., 109, 43

Hanson, A. W., and Cannefax, G. R. (1964). F. Bact., 88, 111

-1 (1965). Brit. F. vener. Dis., 41, 163

Kaplan, H. I., Geating, J. A., and Brooker, C. T. (1968). Laboratory Animal Care, 18, 607

KuHN, U. S. G., BRown, W. J., and Falcone, V. H. (1967. WHO/VDT/RES/68.137

Macfie, J. W. S. (1916). Ann. trop. Med. Parasit., 10, 305

Mothershed, S. M., YoBS, A. R., and Clark, J. W., JR. (1967). Brit. F. vener. Dis., 43, 267

PARR, L. W. (1923). F. infect. Dis., 33, 369.

Pindak, F. F., Clapper, W. E., and Sherrod, J. H. (1965), Amer. F. vet. Res., 26, 1391.

ROSEBURY, T. (1962). 'Microorganisms Indigenous to Man'. Blakiston Division, McGraw-Hill, New York

Steinhaus, E. A., and Hughes, L. E. (1947). Publ. Hlth Rep. (Wash.), 62, 309

Thivolet, J., Sepetjian, M., and Guerraz, T. (1967). WHO/VDT/RES/68. 136

Weber, A. F., and Schmittdiel, E. F. (1962). Amer. $\mathcal{F}$. vet. Res., 23, 422

Isolement de spirochètes chez des primates et chez d'autres espèces de mammifères

\section{SOMMAIRE}

Des mammifères de 19 espèces, de laboratoire ou d'origine sauvage, furent examinés par les méthodes permettant l'isolement d'organismes spirochétiens. Les isolements furent positifs pour au moins un lieu d'inoculation chez tous les carnivores et les omnivores, mais non chez les herbivores. Aucun des specimens recueillis ne put produire de lésion positive au fond noir ou une augmentation du titre d'anticorps pour Treponema pallidum dans l'épreuve du passage au lapin. Cette étude suggère que des spirochètes sont présents dans la flore microscopique de beaucoup d'animaux mais qu'ils restent non découverts tant que l'on emploie pas des méthodes spécifiques pour leur isolement. 